\title{
The Use of Control Mechanisms in Coalition Governments
}

\section{The Role of Preference Tangentiality and Repeated Interactions}

\author{
Albert Falcó-Gimeno \\ University of Barcelona ${ }^{\dagger}$
}

\begin{abstract}
Accepted Manuscript. The final, definitive version of this paper has been published in Party Politics 20(3): 341-356 in 2014 by SAGE Publications Ltd, All rights reserved, (C) Albert Falcó-Gimeno, available online: http://ppq.sagepub.com/content/20/3/341
\end{abstract}

\begin{abstract}
This paper argues that coalitions will tend to employ control mechanisms to facilitate the adoption of compromise policies only when the expected benefit of their use is high enough. When partners are already satisfied with logrolling policies (compartmentalized by jurisdiction) or when compromise is already attainable self-enforcingly, there are few incentives to use them. Conversely, when partners are interested in compromise policies but are unable to reach that outcome in equilibrium, then control mechanisms are likely to be implemented. The empirical evidence offered tends to support the two main hypotheses of this work: control mechanisms are less necessary when the tangentiality of partners' preferences is high and when they foresee frequent mutual interactions. However, that seems to work better for the allocation of watchdog junior ministers rather than for the writing of comprehensive policy agreements.
\end{abstract}

Keywords: Coalition Governments; Control Mechanisms; Preference Tangentiality; Coalition Agreements; Junior Ministers; Western Europe

\footnotetext{
${ }^{\dagger}$ Department of Constitutional Law and Political Science, University of Barcelona, Av. Diagonal 684, 08034 Barcelona, Spain. Email: afalcogimeno@ub.edu.
} 


\section{Introduction}

Coalition governments form between parties that share somewhat complementary interests and allocate portfolios accordingly. As long as an absolute complementarity exists, no problematic bargaining between partners should take place once in office. However, this is seldom the case: “[...] while the parties that make up a coalition may have more or less compatible policy preferences, it is hardly ever the case that all of their policy preferences can be realized simultaneously" (Müller and Strom 2008: 166).

This potential conflict generates a tension between the compromise decisions of the cabinet as a collective body and the individual decisions of its members. ${ }^{\ddagger}$ In fact, both modes of cabinet governance coexist in real-world parliamentary democracies, as reflected in the dual doctrines of individual and collective ministerial responsibility. This is why in coalition politics we find a number of institutions that limit the policy discretion of individual parties in the jurisdictions they control and try to enforce compromise policies through mechanisms of various sorts. For example, junior ministers from one party may be placed to serve under ministers from another party, or several compromise clauses may be written in a detailed policy agreement. Yet not all coalition governments establish this kind of control mechanisms. There is considerable variation among them.

In this paper I adopt a cost-benefit perspective and contend that the establishment of coalition control mechanisms should be expected when their potential benefit is high. More specifically, I argue that when partners are already satisfied with a logrolling outcome where policies are compartmentalized by area (i.e. a collection of parties' ideal points in the jurisdictions each one controls), then there are few incentives to invest in the design of control mechanisms. This is also the case when compromise policies may be already attainable self-enforcingly, without needing any additional device. On the contrary, when partners are interested in compromise policies but they are unable to reach that outcome in equilibrium, I argue that control mechanisms are needed and therefore their use will be more likely.

\footnotetext{
* See, for instance, the debate between Warwick (1999a, b) and Laver and Shepsle (1999a, b) on getting the cabinet decision-making assumptions right.
} 
To advance some findings, I observe that the tangentiality of partners' preference saliencies and their expected mutual interactions make the use of certain control mechanisms less likely. Conversely, coalitions will tend to use them when partners sufficiently care about each others' jurisdictions and they do not expect repeated interactions to automatically lead to compromise. I find that this is the case for the allocation of cross-partisan junior ministers, but only in part for the writing of policy comprehensive coalition agreements.

The remainder of the paper is organized as follows. The following section reviews previous contributions made on the use of control mechanisms in coalition governments and calls attention to a gap to be further investigated. Section 3 presents the theoretical framework and hypotheses of the paper adopting a cost-benefit approach to understand when and why control mechanisms are more or less necessary or useful. Next, I describe the data and variables used in the empirical analyses, the results of which are offered and discussed in the fifth section. Finally, last section concludes and suggests possible paths for future research.

\section{Coalition Control Mechanisms: Agenda Ahead}

Several authors have addressed the question of how coalitions can make their individual members stick to the coalition compromise goals instead of serving their own party objectives (e.g. Strom 2000; Strom et al. 2003; Martin and Vanberg 2004; Thies 2001). Through the departments they run, parties in coalitions could potentially shirk and push the controlled policies to their own ideal point. Different mechanisms have been said to help keep this problem at bay by strengthening cabinet's centralized authority. But apart from largely descriptive accounts of which mechanisms coalitions use, previous literature has seldom dealt with the 'under-what-conditions' question. Only recently some authors have tried to develop causal stories behind the use of these mechanisms in coalition governments.

The few efforts to answer this question have almost exclusively focused on the existent relationship between several mechanisms, both exogenous and endogenous to the specific government. For instance, Müller and Meyer (2010a) argue that control mechanisms complement each other and show that coalition parties that have 
been able to write policy agreements also tend to establish coalition committees and vice versa. Likewise, an election rule and the use of coalition committees appear to go hand in hand. Finally, strong parliamentary committees seem to make coalitions' reliance on ex ante mechanisms more likely (e.g. coalition discipline) but ex post ones unlikely (e.g. watchdog junior ministers).

Along similar lines, others have found that the strength of institutional devices like parliamentary committees (i.e. legislative scrutiny of executive proposals) provides an alternative to other control tools such as the allocation of cross-partisan junior ministers (Thies 2001; Kim and Löwenberg 2005).

Thanks to these approaches we learn that having certain mechanisms make others more or less likely. Yet they keep silent about how the nature of different coalition governments impacts the likelihood of the choice of particular control mechanisms. Put differently, differences in the characteristics of coalition governments are seldom considered as explanatory variables. Nonetheless, the studies made by Müller and Strom (2008), Verzichelli (2008), and also to some extent by Müller and Meyer (2010a) are remarkable exceptions.

The former present an attempt to identify the conditions under which written coalition agreements exist. They do that through an empirical analysis that take several clusters of independent variables, including cabinets' structural characteristics and preferences, countries' political institutions, bargaining environment, and critical events. Their study is however largely conditioned by the structure of the whole book, which studies different phenomena related to coalition governments (i.e. cabinet formation duration, type of cabinet formation, conflict management, cabinet termination and survival, or cabinet membership and electoral performance) using the same clusters of explanatory variables (Strom et al. 2008). ${ }^{\S}$ Hence, their intention is more of an exploratory nature rather than to undertake a test of theory-driven hypotheses. Verzichelli's (2008) work is similarly an empirical exercise mainly, as he studies the allocation of watchdog junior ministers in another chapter of the same book.

\footnotetext{
$\S$ Besides, their dependent variable is just the mere existence of a coalition agreement or not, whereas in this paper we concentrate on policy comprehensive coalition agreements.
} 
Müller and Meyer (2010a) do not only study how different control mechanisms complement each other, but also consider a number of what they call environmental factors. They develop some intuitive arguments about how familiarity, parliamentary bargaining complexity and polarization, policy preference divergence, time, and the institutional environment may impact the use of control mechanisms and test them against the data. They find strong familiarity effects (coalitions tend to adopt control mechanisms used in prior multiparty cabinets) and a tendency of coalitions working under a complex bargaining scenario to turn towards written policy agreements and coalition discipline. Finally, the empirical results also show that cabinets' potential time in office affects coalition partners' willingness to work out a regime of mutual control and that the existence of additional veto players (i.e. strong presidents or second chambers) make parties in coalitions rely less on ex ante control mechanisms.

But beyond these few efforts we still know fairly little about which specific coalition governments are more likely to install certain control mechanisms and why. It is certainly difficult to provide a comprehensive answer to this question, in part due to a lack of reliable information about the true nature of coalition negotiations. It is beyond the theoretical or empirical intention of the following pages to provide a critical analysis of the theories developed so far or to disentangle the whole range of reasons that may drive parties in coalitions to devise mechanisms of mutual control. Nonetheless, this work aims at offering a parsimonious contribution to the study of coalition governance by analysing the influence of certain conditions that, everything else the same, should be conducive to a greater use of control mechanisms in coalition governments. More concretely, the 'under-what-conditions' question is first clearly stated, hypotheses are then derived from a cost-benefit theoretical approach, and finally empirically tested against the data.

\section{When and Why Use Them? A Cost-Benefit Approach}

So when and why will coalition partners choose to establish a certain toolkit of control mechanisms so as to keep tabs on each other? The decision to invest in the design of the mentioned mechanisms could well be approached from a cost-benefit perspective. To make this kind of decisions, parties must incur several sorts of costs 
which can in turn vary depending on a number of conditions (Kreps 1990). "Setting up coalition governance mechanisms is therefore costly. Specifically, it entails transaction costs" (Müller and Strom 2008: 185). Strom and Müller (1999) explicitly conjecture that "[c]omplex bargaining situations heighten transaction costs, and high transaction costs lead to the adoption of less comprehensive agreements". Or the other way around: they "expect to see more complete agreements, and more elaborate institutions for their enforcement, the lower the relevant transaction costs". So one possible answer of the question entitling this section is that coalitions tend to use control mechanisms when the associated costs are lower. The why is here obvious: higher costs make the design more expensive.

But the cost-benefit approach has another side. The benefit one. Keeping costs constant, the higher the potential benefit of installing a control mechanism, the more profitable it will be. Hence, the rationale goes, a given coalition will be more likely to establish these controls the more their expected benefit. Analyzing coalition agreements, Müller and Strom (2008: 160) put it this way: "We also expect that the

greater the need for coalition agreements, the more common and elaborate such agreements will be". Likewise, Müller and Meyer (2010a: 15) write that "[c]oalitions are more likely to employ the control mechanisms outlined here if the potential gains are high". Yet how can we account for such a potential need or benefit?

The first step is to think in counterfactual terms: What would have happened had the mechanisms been absent? This article claims that the potential benefit of coalition control mechanisms varies under different circumstances. Most importantly, I concentrate on the type of preferences of the partners sharing office, and also on how likely are their mutual interactions in subsequent government formations.

\subsection{The counterfactual: Preference tangentiality and repeated interactions}

According to Luebbert (1986), the preferences of coalition parties can be either convergent, divergent, or tangential. Convergence and divergence are in fact two sides of the same coin. The difference between the two is pretty obvious, namely, the extent to which partners hold conflicting views over a given issue. The ideal points of 
cabinet members can be closer (i.e. convergent) or farther apart (i.e. divergent). However, holding convergence/divergence constant, tangentiality can in addition characterize the preferences of the members of a coalition government. Unlike the former, tangentiality has nothing to do with positions and "is really a matter of the relative salience of issues to parties as coalition members". The interests of coalition partners are tangential when "issues are of differing salience to different parties; one party may emphasize cultural issues but be relatively indifferent about economic issues, while a coalition partner may weight the issues in the opposite way" (Andeweg and Timmermans 2008: 276). ${ }^{* *}$ In this paper I concentrate on this coalition governments' ideological characteristic.

In Figure 1 we can see a spatial illustration of what we understand by tangentiality.

\section{[FIGURE 1 ABOUT HERE]}

The two-dimensional ideal point of party A is ¡Error!, whereas for party B it is $i$ Error!. In the lattice on the left the two policies $\mathrm{X}$ and $\mathrm{Y}$ are equally salient both for party A and B. This is represented by the perfectly circular indifference curves (solid black lines). In the graph on the right, though, parties do not care equally about both policies. For party A, dimension $\mathrm{X}$ is more salient, while party $\mathrm{B}$ cares more about dimension Y. The latter is represented with the solid black ellipses and it is what I refer to when talking about tangential preferences. Conversely, I will label the situation of the saliences in the left graph as overlapped preferences (the overlap area is larger).

Let me now assume that these two parties, A and B, have formed a coalition government and allocated the two portfolios related to the policy jurisdictions $\mathrm{X}$ and Y. The former is given to party A and the latter to party B. If we simplify the situation a little, there are basically two policy packages that can be implemented. In one of them, party A will set policy $\mathrm{X}$ at its ideal point $\left(X_{A}\right)$, while party $\mathrm{B}$ will push policy $\mathrm{Y}$ to $Y_{B}$. Alternatively, the implemented policies can be ¿Error! on the contract curve, in the shaded compromise area. In the former, each partner lets the

\footnotetext{
** Emphasis added.
} 
other set the policies it wants in the jurisdiction(s) it controls in exchange for being allowed to do the same in its own jurisdiction(s). This would be a compartmentalized cabinet, where the coalition makes policies not as a product of issue-by-issue compromises, but as a logroll of party ideal points (Thies 2001). Compromise policies, on the other hand, would be those in the shaded area. These policy combinations are preferred by partners since all points in the compromise area are closer to both parties' ideal points than the 'logroll' or 'compartmentalization' point is.

In a situation of tangential preferences, though, 'logrolling' is a simple way to resolve partners' 'differences in emphasis' (De Winter 2002). In other words, the policy package ¡Error! is very close to the best compromise point possible. However, when the situation is one where coalition members' preferences are not tangential, the implementation of policies ¡Error! would generate a more serious problem. The opportunity costs associated to such policy package would be higher given that some points in the compromise area would be much preferred by both partners.

This article contends that preference tangentiality makes partners happy enough with the only credible and incentive-compatible policy package (Thies 2001) which "depends only on giving ministers the power to do what they expressly want to do. Any proposal promising that a minister with wideranging power over the relevant policy jurisdiction will act against expressed preferences is less credible" (Laver and Shepsle 1990: 874). That would make control mechanisms essentially useless, since the counterfactual of what would have happened in their absence is good enough. In other words, the potential benefit of these mechanisms would be low since, spatially, there is little to gain when the parties of a coalition government have tangential preferences. Applying control mechanisms in this situation would probably not be worth the effort.

Therefore, control mechanisms would be potentially beneficial only when there exist compromise policy packages ¡Error! that are clearly better than the 'logroll' point ¡Error!. That is, under a low tangentiality (high overlap) of their saliences. However, others have suggested that parties in coalition governments may behave 
cooperatively and implement compromise policies even without control mechanisms provided that they anticipate repeated interactions in the future (Müller and Strom 2008). This is well in line with the predictions of the literature on contract economics, which emphasizes parties' incentives to preserve their reputation to be credible in future interactions (e.g. Chen 2000; Stiglitz 2000; or Aghion et al. 2002). Hence, without needing any additional (control) mechanism, parties would be able to reach the point they prefer self-enforcingly, as long as they found it sufficiently likely to meet their partners repeatedly. Under such circumstances the potential usefulness of coalition control mechanisms would be practically unexistent, as the preferred outcome would be already achieved without having to pay the transaction costs of their establishment.

Note that in this whole argument the self-enforcing policy equilibrium conducive to the choice of control mechanisms appears sequentially after the assumed allocation of portfolios between partners. Several empirical studies of coalition formation processes, though, have concluded that the division of portfolios among parties and the appointment of ministers takes place at the end of the cabinet formation process. Hence, the policy pertaining to the various jurisdictions is likely to be agreed according to either some form of compartmentalization or compromise prior to the actual allocation of ministerial portfolios, which is not exactly the sequence behind the theory above.

Nonetheless, what the argument assumes is that the eventual allocation of portfolios is consistent with and endogenous to the type of preferences of the partners and to the resulting policy equilibrium, beyond the specific bargaining sequence. In fact, the empirical studies mentioned above also acknowledge that portfolio allocation may be anticipated by partners or informally dealt with during policy talks. The built-in assumption is actually that the allocation of portfolios will match the degree of preference tangentiality of the partners in office, who will get the portfolios on the policy dimensions that are more salient to them. This assumption finds support in Bäck et al. (2011), who demonstrate empirically that parties that claim more 
intensely certain policy jurisdictions in their manifestos are more likely to receive the related portfolios, controlling for other factors. ${ }^{\dagger \dagger}$

\subsection{When are control mechanisms needed? Main hypotheses}

To recapitulate, three different scenarios emerge in terms of the potential benefit of control mechanisms in coalition governments. They are summarized in the diagram of Figure 2.t+

\section{[FIGURE 2 ABOUT HERE]}

In the first two situations control mechanisms are not necessary but for slightly different reasons. When parties sharing office have tangential preferences (i.e. they care about a concrete group of policy areas and not much about those controlled by their partners), then a fully labor-divided cabinet (i.e. compartmentalized) is itself optimal, as partners are content enough with the policies such a cabinet produces. And that is regardless of how they evaluate the likelihood of mutual interactions. Control mechanisms would therefore be useless as parties already like the 'uncontrolled' outcome. On the other hand, when partners' preferences overlap (i.e. they care enough about what happens in the jurisdictions controlled by the others in cabinet), the compromise deal is the one they prefer. However, they may still find no need to install control mechanisms if all partners value sufficiently the likelihood of mutual interactions. If so, a compromise cabinet would be in (a self-enforcing) equilibrium and thus the preferred outcome would be already reached without needing any investment in additional controls. ${ }^{\S}$

\footnotetext{
${ }^{\dagger}$ I thank one of the reviewers for inviting to clarify the implicit assumption that is indeed behind the argument.

$\$$ The shaded boxes stand for the government-dependent conditions (or in other words, independent variables) that configure the different scenarios.

$\S \S$ In a similar vein, Müller and Strom (2008: 181-2) state that "[p]arties have incentives to preserve their reputation so as to be credible in future negotiations. Moreover, party leaders will care about their cabinet members remaining faithful to the coalition agreement even when the latter are tempted to exploit their private information at the expense of their coalition partners. Party leaders may keep such behavior in check because they have to keep in mind the big picture and preserve their party's (and their own) reputation".
} 
Yet there is a third scenario in which establishing control mechanisms may be necessary or potentially useful for coalition partners. When compromise is the preferred outcome (i.e. when partners have overlapping preferences), but their low valuation of repeated interactions makes compromise not to be in equilibrium, then coalition control mechanisms may be needed. It is precisely under the circumstances embodied in situation III (see Figure 3), when partners in coalition governments may find it worth the effort to keep tabs on each other through a series of control mechanisms. Thinking counterfactually, this is the only scenario in which if no further mechanisms were established, the self-enforcing outcome would be one disliked by the partners in office.

\section{[FIGURE 3 ABOUT HERE]}

This argument provides a theoretical account about certain conditions under which 'coalition architects' may find it cost-beneficial to place control mechanisms in the cabinet. We can hypothesize that keeping the costs (and everything else) constant, the more the potential benefit of a control mechanism, the more the incentives to install one. What I do in this paper is no more (no less) than checking to what extent there is an empirical correspondence between the situations in which coalition control mechanisms would be potentially useful or necessary, and their actual use. The first two related hypotheses are the following:

Hypothesis 1: The more the tangentiality of coalition partners' preferences, the less likely the establishment of coalition control mechanisms.

Hypothesis 2: The more coalition partners value the possibility of repeated mutual interactions, the less likely the establishment of coalition control mechanisms.

In fact, these two hypotheses are well in line with Müller and Strom's (2008:

166) intuitions regarding written coalition agreements:

Not every situation that allows coalitions to form may require a formal coalition agreement. In some cases, the preferences of the parties may be sufficiently well aligned that there is no need to negotiate a formal agreement. Alternatively, party leaders may behave cooperatively even 
without such an agreement if they anticipate either repeat interactions in the same arena or other interactions in different arenas. ${ }^{* * *}$

Notice also that there is a third hypothesis implicit in Figure 2's diagram. Regardless of the extent to which partners value the repetition of their interactions, control mechanisms are unnecessary if their preferences are sufficiently tangential (scenario I). In other words, the tangentiality of partners' preferences should only make a difference when partners' valuation of repeated mutual interactions is low enough. In that case, they will envisage mechanisms of mutual control when their preferences overlap (scenario III), but they will find no need to do so under preference tangentiality. The implicit interactive hypothesis is then obvious:

Hypothesis 3: The more partners value the possibility of mutual interactions, the weaker the (negative) effect of preference tangentiality on the likelihood of establishing coalition control mechanisms.

These hypotheses -and in fact the whole argument- obviously rely on the implicit assumption that control mechanisms do effectively make compromise policies more likely and contain potential deviations from cabinet members. Or at least, it requires parties to think they are effective. I will briefly reflect on the implications of that below, in the explanation of the dependent variables and discussion of the results.

\section{Data and Variables}

In order to test empirically the hypotheses posed above I use information coming from four different datasets.

On the one hand, I relied on a dataset based on the joint work of numerous country experts offering extensive data on coalition governments of 17 West European countries (Müller and Strom 2000; Strom et al. 2003, 2008). It provides information on 424 cabinets, of which 260 are coalition governments, and covers the period beginning with the first post- II World War (democratic) cabinet up to 2000 .† $^{\dagger \dagger}$

\footnotetext{
*** Emphasis added.

${ }^{\dagger \dagger}$ For further details see Bergman et al. (2008).
} 
The dependent variables of this paper come from this dataset. They are the Existence of a Comprehensive Policy Agreement in that coalition government (as coded by country experts), the Establishment of Cross-Partisan Junior Ministers, and the Share of Cross-Partisan Junior Ministers in that cabinet.

Coalition agreements exhibit a great deal of variation, running all the way from very general informal understandings (gentlemen's agreements) to very detailed formal documents (contract-like written documents) (Müller and Strom 2008). Written agreements can also vary a lot in terms of size, contents, and comprehensiveness, with significant differences across time and across countries. Since I am substantively interested in the way coalitions try to reach policy compromises beyond a mere collection of parties' ideal points in the respective jurisdictions, I will here consider agreements based on a written comprehensive policy programme. Such documents are generally rather specific 'contracts' that spell out exhaustively and in great detail to what extent participants commit themselves to a broad range of policy initiatives. ${ }^{*+}$ In fact, one critical choice that a coalition has to make at its outset is about how detailed a policy agreement, if any, should be (Müller and Strom 2008: 174, 182). Consequently, the first dependent variable takes value ' 1 ' when coalition partners fix their compromises in a written comprehensive policy agreement and ' 0 ' otherwise.

Some have argued that these types of coalition agreements, even detailed ones, are little less than window dressing. As acknowledged by Müller and Strom (2008) and Müller and Meyer (2010b), none of these mechanisms is truly enforceable. There is no such thing as a third-party institution that unambiguously sanctions deviations from the contents of this 'contract'. Enforcing such contracts, therefore, may require parties to be interested in observing them in the first place. If so, written coalition agreements would not actually be control mechanisms. On the contrary, parties may only be interested in the formalization of a comprehensive agreement when they can be rather sure that the clauses will be observed when it comes the time to make

\footnotetext{
\#\# In the terminology of Royed (1996), such an agreement would contain more definite pledges relative to difficult and rhetorical ones. In Luebbert's (1986) terms, explicit compromises would dominate over implicit ones.
} 
policies. If that is the case, then the expectations regarding the influence of the main independent variables on the writing of comprehensive policy agreements would not be those put forward in the hypotheses above. However, I stick by now to the consideration of coalition agreements as 'effective' control mechanisms and leave for the discussion of the results a further assessment of this issue.

The other two dependent variables refer to institutions that are thought to keep an eye on the actions undertaken by the other partners in their own ministries: the allocation of watchdogs (junior ministers) in the other partners' jurisdictions, both measured through a dichotomous variable (Establishment) and through the proportion of ministries containing junior ministers (Share). The latter is especially interesting as it can capture a much more nuanced cross-cabinet variation than the 0-1 variable in which a single watchdog junior minister is sufficient to classify a given cabinet as having this type of governance mechanism. ${ }^{\S \S}$

Hence, as dependent variables I am concentrating on two specific control mechanisms, the writing of a comprehensive policy agreement and the establishment of junior ministers. These are clearly the two most studied institutions when academics have inquired about how coalitions manage the control of their bargains. Therefore, the combination of the two can provide a good overview of the control mechanisms that multiparty governments establish (e.g. Strom and Müller (1999), Müller and Strom (2008), Timmermans (2003, 2006), Timmermans and Andeweg (2000), or Moury (2011) for coalition agreements; and Thies (2001), Manow and Zorn (2004), Verzichelli (2008), or some chapters in Müller and Strom (2000) for junior ministers).

Three independent (control) variables do also come from the aforementioned database. The first is the Maximum Possible Cabinet Duration at the time of formation -before the next scheduled election-. ${ }^{* * * *}$ According to Müller and Strom

\footnotetext{
$\S \S \S$ I thank Thomas Meyer and Wolfgang C. Müller, from the Mannheim Centre for European Social Research (MZES, University of Mannheim), for making this share variable available to me, which was not directly obtainable from the public dataset.

**** This variable is originally measured in number of days but it has been transformed in month units here. However, in the transformation process, it has not lost its fine-graininess (i.e. 40 days $=1.33$ months).
} 
(2008: 192-3), the longer the time horizon of the current coalition, the higher the uncertainty to be faced, and therefore the more restrictive the inter-partners' control should be. Similarly, the higher the Cabinet Preference Range (Polarization), the more parties are expected to disagree about policy, and thus the more interested they will be in centralized mechanisms of policy commitment. ${ }^{\dagger+\dagger}$ Finally, would-be partners present in some cases a joint pre-electoral declaration to signal their readiness to join in a future government with a common agenda. These documents can be easily amended or accompanied by further agreements after electors have casted their votes, possibly decreasing the costs of hammering out post-election control mechanisms. Hence, a dichotomous variable characterizes the existence or absence of a Preelectoral Agreement.

As summarized above, other studies have focused on the effect of legislative institutions on the way parties in coalitions control each other. Kim and Löwenberg's (2005) account of oversight institutions -German parliamentary committees- as devices for the enforcement of coalition treaties is one good example. Likewise, Martin and Vanberg $(2004,2005)$ claimed that, in order to enforce the coalition bargain, parties make use of parliamentary institutions to scrutinize the proposals of their partners' ministers to which they have been forced to delegate important agenda-setting powers. Countries vary in this institutional aspect -and sometimes even within a country across time- making legislative review more or less costly. Then, the easier parties find it to control their partners' proposals through amendment procedures in parliament, the less necessary additional control mechanisms outside the legislative should be, and vice versa.

I have trusted in two different variables to measure the strength of legislative oversight institutions. First, the presence of Permanent Committees as opposed to ad hoc ones. This is a dichotomous variable that takes the value ' 1 ' when there exist legislative review committees on a permanent basis, and ' 0 ' when they need to be

\footnotetext{
ti† Although offered in the Strom-Müller-Bergman dataset, the information of this variable originally comes from the Comparative Manifestos Project (Budge et al. 2001) and indicates the maximal distance in terms of left-right positions between the government parties (in manifesto points).
} 
called ad hoc or when this institution simply does not exist. Everything else the same, parliamentary review should be more costly in the latter situation than in the former (Strom et al. 2003). The specific data comes from Bergman et al. (2003). Secondly, I also incorporate the variable (legislative) Committees' Power. It is an additive index that provides scores on their role, authority to rewrite, and timetable control, building on three variables coded by Döring (1995). Clearly, this variable is better than the first one as it offers a much more nuanced variability. However, it has the disadvantage of coming from a 'snapshot' taken in 1989, although we can suspect that this kind of institutions seldom vary across time. Hence, I assigned the one-point-in-time value to the rest of the years for each country (just like Tsebelis (2007) or Müller and Meyer (2010a) do), but simultaneously kept the variable Permanent Committees for which we do have across-time information.

All the above described variables have been said to affect the likelihood of coalition governments to resort to control mechanisms. They have been incorporated in the empirical tests as controls to try to isolate the effect of this paper's substantive explanatory variables: partners' preference tangentiality and valuation of mutual interactions. The process followed to operationalize them is explained in detail next.

\subsection{Partners' preference tangentiality}

For the first main independent variable, we have to measure how much parties in coalition governments care about different policy dimensions. If the interests of different parties are very intense in the same areas, then their preferences will be overlapping. Put the other way around, when coalition partners care a lot about some policies, but not the same ones as their partners, then their tangentiality in saliency terms is high and the overlap low. That is, they will be hardly interested in what their partners do in their issues while being rather free to do what they want in their own ones without causing much uproar.

Fortunately, this saliency approach to preference tangentiality (holding polarization constant) fits very well to one of the few data sources on parties' preferences varying across time: the Comparative Manifestos Project (CMP) data. 
This project codified the content of different parties' documents by classifying each quasi-sentence in different categories (for details see Budge et al. (2001)).

These categories are rather narrow. To make sense out of them I followed Bäck et al.'s (2011) attachment of CMP categories to 13 policy jurisdictions with a greater theoretical substance. Each of these new groups contained the sum of scores in the more specific CMP categories, resulting in a party-specific overall score of saliency for each policy jurisdiction. To transform this measure into a government-specific one, I computed the cabinet standard deviation of these saliences for each jurisdiction and finally calculated the mean of them to have an overall measure of the degree of preference complementarity in the coalition cabinet. Clearly, taking the saliency approach, the higher the average standard deviation, the more tangential are partners' preferences (holding positions -not saliences- constant). The resulting variable is Preference Tangentiality.

\subsection{Partners' valuation of mutual interactions}

The second substantive independent variable captures to what extent parties in coalition governments value the likelihood of mutual interactions. This valuation is no more than an intertemporal calculus that each partner in the coalition makes. In this calculus parties evaluate whether it is likely or not that their current partners need be partners again in subsequent government formations. According to the second hypothesis, the higher this expected likelihood, the more likely is the emergence of self-enforcing compromise, and thus the less needed are coalition control mechanisms.

Obviously, there is no direct way to observe how parties evaluate such a probability and therefore we have to rely on proxies. The strategy followed in this paper is based on the actual composition of cabinets through time. For each member in the coalition I calculated the proportion of cabinets equal to the current cabinet out of the total number of cabinets in which the party participated during the studied period. To make it a government-specific value, I attributed each cabinet the one from the party with the lowest value, what gives the variable Likelihood of Partners' Interactions (Min. Value). This measure is consistent with the theoretical approach as 
compromise would not be observed if one single member of the coalition did not see their partners as frequent travel mates, which would push the behavior of the whole coalition toward a non-compromise scenario.

This is certainly a rough approximation to the intertemporal calculus that the parties in a coalition office may have in mind. It basically measures the degree of familiarity between partners counting the frequency of cabinets in the whole period of analysis. As it will be discussed in the next section, the behaviour of this variable is not the expected one for the case of written coalition agreements, which might be attributed to substantive theoretical reasons but also to the characteristics of the measurement.

The source for the operationalization of the two main independent variables comes, mainly, from the CMP data and the procedure in Bäck et al. (2011). The article has also used the 'Parties, Governments and Legislatures Data Set' (Cusack et al. 2007), which compiles different sources of information in the same database. A couple of descriptive statistics of the variables Preference Tangentiality and Likelihood of Partners' Interactions (Min. Value) are summarized, by country, in Table 1 .

\section{[TABLE 1 ABOUT HERE]}

As we can see, both variables vary considerably both between and within countries.

\section{Empirical Analysis}

I use logistic regressions to explain the establishment of cross-partisan junior ministers and the writing of comprehensive policy agreements. To predict the share of 'watchdog' junior ministers in the cabinet linear regression models are estimated. Results are displayed in Tables 2, 3, and 4.

\section{[TABLE 2 ABOUT HERE]}

\section{[TABLE 3 ABOUT HERE]}

[TABLE 4 ABOUT HERE]

The first thing that stands out from the three tables is the systematic effect of preference tangentiality both for the allocation of cross-partisan junior ministers and 
the writing of a policy comprehensive coalition agreement. In model (2) of both Tables 2 and 3 we see that the higher the tangentiality of preferences between the parties in office, the less need they find in placing junior ministers in the jurisdictions of their partners to monitor their actions. That is, when parties do not care much about the issues that are salient for the partners that share office with them, they have little incentive to worry about allocating junior ministers to serve under ministers with other partisan loyalties. Interpreted in the opposite direction, the more partners' preferences overlap, the more they tend to trust in junior ministers as tools for mutual control. That seems to work both for the dichotomy between allocating or not (Table 2) and for the continuous share of junior ministers (Table 3): the coefficients of Preference Tangentiality have the expected negative sign and reach conventional levels of statistical significance.

As for the writing of detailed policy commitments in a coalition agreement, the same mechanism appears to hold empirically (see Table 4). As hypothesized, coalition cabinets with a high preference tangentiality between partners are less likely to invest in the writing of a constraining policy agreement with clear clauses on what each party should do in the jurisdictions under its control.

Unlike with the first hypothesis, the empirical support to the second one is only partial. For junior ministers, the effect of the variable Lik. of Partners' Interact. (MV) works as expected (Tables 2 and 3). The more likely the repetition of the current government, the less likely the use of these sorts of control mechanisms. As argued in section 3, the rationale is that parties in cabinets expecting to meet frequently are more inclined to pursue compromise policies (which will pay off in the long-term through the formation of subsequent governments) instead of succumbing to the (short-term) temptation of deviating to the individual party's ideal point. That is, partners in 'frequent' cabinets tend to take a more long-sighted view and play compromise more often, leading to the emergence of self-enforcing deals. The fact of being self-enforcing is precisely what makes external devices to enforce compromise unnecessary. That holds empirically both for the $0-1$ establishment and for the share of watchdog junior ministers in the cabinet. 
Yet in Table 4, the effect of the variable Lik. of Partners' Interact. (MV) seems to run in the exact opposite direction. Coalitions likely to form repeatedly over time are precisely those more prone to write comprehensive agreements with detailed policy clauses. This empirical finding would be inconsistent with the expectation derived in the theoretical part. It seems to be the case that precisely those multiparty governments that would observe the compromise anyway are those that generally write their compromises on paper.

Previous scholarly research has found that most of the policies agreed up front in the coalition 'treaty' are finally implemented (e.g. Müller and Strom 2000; Timmermans 2003, 2006; or Timmermans and Moury 2006), or at least help in containing controversy and conflict by pre-cooking policies (Klingemann et al. 1994; Keman 2002; Timmermans 2003; Moury 2011). Similarly, Müller and Strom (2008: 164-5) state that: "[c]oalition agreements exist, and they are designed to cement deals that might otherwise come unstuck". But immediately add "[a]s long as the coalition parties faithfully observe the agreement [...]”. As Timmermans (2006: 272) puts it, "[t] he principle of pacta sunt servanda (agreements must be observed) is noble, but it needs reciprocal control among coalition parties". Even if one partner detects the other is not being faithful to the deal, it will have no means other than political means to make the latter behave. So it appears that the fulfilment of the range of policy initiatives to which will-be partners commit on paper is endogenous to the coalition parties' self-interest. In other words, coalition agreements may only be observed provided that they are self-enforcing.

The problem is that if it is in the best interest of parties to respect and enforce the deal (because of reputation, mutual interactions, etc.), then it was in their best interest to adopt compromise policies in the first place, regardless of the written agreement. And that makes coalition agreements lose sense as a control mechanism with a causal effect in keeping individual partners on compromise tracks. So, inductively, we could conjecture that formal coalition agreements are no more than written documents putting together what the multiparty cabinet expects to accomplish during their term in office rather than to overcome difficult situations of uncertainty, mistrust, opportunism, or preference divergence and make possible policies that 
would not be implemented otherwise. Due to enforcement problems, coalition agreements could only be redundant in the sense that they would write on the stone what would be done regardless. In contrast, when self-enforcement compromise is unworkable parties would anticipate likely non-observance and leave explicit compromises unwritten. ${ }^{\text {Htt }}$

Timmermans (2006: 268) identifies "[...] two strategies in government formation situations of mistrust, uncertainty and policy conflict. One is to make commitments as detailed as possible; the other strategy is to forego clear commitments and keep policy options open". He argues that the second strategy will be chosen when parties discount future more. One way to understand this discount rate is the expected non-fulfilment of a detailed coalition treaty due to partners' low consideration for future mutual agreements. This would be consistent with what the

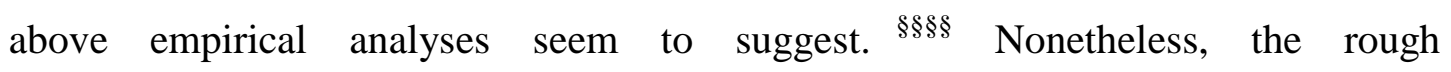
operationalization of the variable measuring partners' valuation of future interactions -which basically counts the frequency of cabinets in the whole period studiedshould probably invite caution in taking this conjecture too far. Higher familiarity could for instance mean less need to write the coalition agreement but at the same time less costs and higher intertia to do so. At any rate, these interesting implications for the writing of comprehensive policy agreements do merit further inquiry.

As for the interactive hypothesis of the paper, we can conclude that it works reasonably well too, although the empirical support is again partial. The (negative)

$\$+$ Alternatively, it may well be the case that those cabinets that did not trust in the observance of an agreement opt for other type of control mechanisms to push policies closer to the optimal compromise point. For instance, they could resort to ex post controls (e.g. junior ministers) while avoid committing to any specific policy agenda.

§§§§ Timmermans and Moury (2006) also offer anecdotal evidence in this direction. They detected that "cabinets with an unusual or even unprecedented party combination, Dehaene I and Kok I, had a relatively brief coalition agreement containing a comparatively small proportion of precise intentions", with very clear examples such as the 1994 PVDA-VVD-D66 coalition in the Netherlands in which " $\mathrm{t}]$ he three parties negotiated a coalition agreement dealing with issues on which the Liberals and Social Democrats were furthest apart, but which did contain less details than could be expected given their new experience in office together". 
effect of the tangentiality of partners' preferences on the appointment of watchdog junior ministers is weaker as the likelihood of repeated interactions increases. As suggested in the theoretical section, coalition cabinets where parties have tangential preferences are already happy with the self-enforcing decentralized outcome and have little incentive to enforce compromise policies that they do not like better; and that is regardless of how likely it is that they see their faces in other governments. By contrast, partners with overlapping preferences should be much more interested in achieving a compromise outcome. Such a compromise outcome would be already in a self-enforcing equilibrium if the likelihood of repetition was high enough, yet if it wasn't, control mechanisms such as junior ministers would be needed to enforce the compromise. Once more, though, that seems to work empirically for the allocation of cross-partisan junior ministers and not for the establishment of a written policy comprehensive agreement.

\section{[FIGURE 4 ABOUT HERE]}

Figure 4 shows graphically how the predicted probabilities of appointing (at least one) cross-partisan junior minister(s) vary depending on how likely it is the repetition of partners' mutual interactions, for cabinets with different degrees of preference tangentiality. The predicted probabilities and $90 \%$ confidence intervals are generated for two groups of cabinets, one with highly tangential preferences (value of the ninth decile of the variable Preference Tangentiality, solid line) and the other with a low level of tangentiality (first decile, dash-dotted line). ${ }^{* * * * *}$ The graph clearly shows that the difference between cabinets with preference tangentiality and overlap is largest when the probability of mutual interactions is lowest. Instead, if the latter is high, coalitions will not find it necessary to install such control mechanisms irrespective of the degree of preference tangentiality in cabinet.

\section{Conclusion and Outlook}

This paper has dealt with the understudied topic of the conditions under which coalition governments devise control mechanisms to ensure a centralized governance

\footnotetext{
***** Value in the 10th percentile of the ordered distribution of Preference Tangentiality equals 2.24 , while the one in the 90th is 6.86 .
} 
instead of a compartmentalized one. It is said that the former allows the adoption of compromise policies that make partners better-off, while the latter tends to produce suboptimal policies that simply reflect a collection of parties' ideal positions in their respective jurisdictions. The problem is that compromise policies are not always easy to obtain given the strong agenda powers that each party has in their portfolios. Control mechanisms, it has been contended, facilitate the achievement of such optimal policies and thus coalitions will in general be interested in working them out.

It is the case, though, that some do and others do not. This work has argued that we should expect multiparty cabinets to install such mechanisms particularly under those circumstances that make them potentially necessary and beneficial. These favorable scenarios have been identified as those in which partners both i) have preferences that are not tangential and ii) do not value much mutual interactions. If the former condition is not met then control mechanisms are senseless because partners with a high preference tangentiality already like a compartmentalized or 'logroll' policy package, while if the latter is not, then they are unnecessary because compromise policies would be attained regardless.

The emerging three hypotheses (including an interactive one) have then been tested against the data. Preference tangentiality has appeared as a strong determinant of the allocation of cross-partisan junior ministers as well as of the writing of comprehensive policy agreements. The more tangential they are, the less incentives parties have to install mechanisms of mutual control. However, the evidence for the likelihood of repeated interactions has been more ambiguous: the more partners expect to repeat in government, the less they need to place junior ministers in the jurisdictions controlled by the other partners, but also the more they tend to write detailed agreements. That might suggest that coalitions facing a high probability of compromise non-observance avoid committing to a comprehensive policy agenda and turn to incomplete contracts instead. Detailed coalition agreements might only be able to put on paper, redundantly, what would be done regardless.

These findings and conjectures, and in particular the role of preference tangentiality on other phases of the coalition life cycle beyond the use of control mechanisms -such as formation, portfolio allocation, termination, and also 
governance more broadly- does merit further attention. This paper has tried to provide both a theoretical and an empirical account of certain conditions that make the use of control mechanisms in coalitions more likely. In so doing, some questions have been answered and new ones have been opened. Future research is thus needed, and there is every reason to believe that such efforts will help improve our understanding of the use of control mechanisms and of coalition governance more generally.

\section{References}

Aghion, Philippe, Mathias Dewatripont, and Patrick Rey (2002) 'On Partial Contracting', European Economic Review 46: 745-53.

Andeweg, Rudy B. and Arco Timmermans (2008) 'Conflict Management in Coalition Government', in Kaare Strom, Wolfgang C. Müller, and Torbjörn Bergman (eds) Cabinets and Coalition Bargaining: The Democratic Life Cycle in Western Europe. Oxford: Oxford University Press.

Bäck, Hanna, Marc Debus, and Patrick Dumont (2011) 'Who Gets What in Coalition Governments? Predictors of Portfolio Allocation in Parliamentary Democracies', European Journal of Political Research 50: 441-78.

Bergman, Torbjörn, Wolfgang C. Müller, Kaare Strom, and Magnus Blomgren (2003) 'Democratic Delegation and Accountability: Cross-National Patterns', in Kaare Strom, Wolfgang C. Müller, and Torbjörn Bergman (eds) Delegation and Accountability in Parliamentary Democracies. New York, NY: Oxford University Press.

Bergman, Torbjörn, Elisabeth R. Gerber, Scott Kastner, and Benjamin Nyblade (2008) 'The Empirical Study of Cabinet Governance', in Kaare Strom, Wolfgang C. Müller, and Torbjörn Bergman (eds) Cabinets and Coalition Bargaining: The Democratic Life Cycle in Western Europe. Oxford: Oxford University Press.

Budge, Ian, Hans-Dieter Klingemann, Andrea Volkens, Judith Bara, and Eric Tannenbaum (2001) Mapping Policy Preferences. Oxford: Oxford University Press. 
Chen, Yongmin (2000) 'Promises, Trust, and Contracts', Journal of Law, Economics, and Organization 16: 209-32.

Cusack, Thomas R., Susanne Fuchs, and Kathrin Müller (2007) 'Parties, Governments, and Legislatures Data Set'.

De Winter, Lieven (2002) 'Parties and Government Formation, Portfolio Allocation, and Policy Definition', in Kurt R. Luther and Ferdinand Müller-Rommel (eds) Political Parties in the New Europe: Political and Analytical Challenges. New York: Oxford University Press.

Döring, Herbert (1995) Parliaments and Majority Rule in Western Europe. New York, NJ: St. Martin's Press.

Keman, Hans (2002) 'The Low Countries: Confrontation and Coalition in Segmented Societies', in Political Institutions in Europe, Edited By J. M. Colomer. London: Routledge.

Kim, Dong-Hun and Löwenberg (2005) 'The Role of Parliamentary Committees in Coalition Governments: Keeping Tabs On Coalition Partners in the German Bundestag', Comparative Political Studies 38: 1104-29.

Klingemann, Hans-Dieter, Richard I. Hofferbert, and Ian Budge (1994) Parties, Policy, and Democracy. Boulder: Westview Press.

Kreps, David M (1990) A Course in Microeconomic Theory. Princeton, NJ: Princeton University Press.

Laver, Michael J. and Kenneth A. Shepsle (1990) 'Coalitions and Cabinet Government', American Political Science Review 84: 873-90.

- (1999a) 'Understanding Government Survival: Empirical Exploration Or Analytical Models', British Journal of Political Science 29: 395-401.

— (1999b) 'Government Formation and Survival: A Rejoinder to Warwick'S Reply', British Journal of Political Science 29: 412-5.

Luebbert, Gregory M (1986) Comparative Democracy: Policymaking and Government Coalitions in Europe and Israel. New York, NY: Columbia University Press.

Lupia, Arthur and Kaare Strom (2008) 'Bargaining, Transaction Costs, and Coalition Governance', in Kaare Strom, Wolfgang C. Müller, and Torbjörn Bergman 
(eds) Cabinets and Coalition Bargaining: The Democratic Life Cycle in Western Europe. Oxford: Oxford University Press.

Manow, Philip and Hendrik Zorn (2004) 'Office Versus Policy Motives in Portfolio Allocation the Case of Junior Ministers', MPIfG Discussion Paper 04/9.

Martin, Lanny W. and Georg Vanberg (2004) 'Policing The Bargain: Coalition Government and Parliamentary Scrutiny', American Journal of Political Science 48: 13-27.

Martin, Lanny W., and Georg Vanberg (2005) 'Coalition Policymaking and Legislative Review', American Political Science Review 99: 93-106.

Moury, Catherine (2011) 'Coalition Government and Party Mandate: How coalition agreements constrain the ministers', Party Politics 17: 385-404.

Müller, Wolfgang C. and Thomas Meyer (2010a) 'Meeting the Challenges of Representation and Accountability in Multi-Party Governments', West European Politics 33: 1065-92.

- (2010b) 'Mutual Veto? How Coalitions Work', in Thomas König, George Tsebelis, and Marc Debus (eds) Reform Processes and Policy Change: Veto Players and Decision-Making in Modern Democracies. New York: Springer.

Müller, Wolfgang C. and Kaare Strom (2000) Coalition Governments in Western Europe. Oxford: Oxford University Press.

- (2008) 'Coalition Agreements and Cabinet Governance', in Kaare Strom, Wolfgang C. Müller, and Torbjörn Bergman (eds) Cabinets and Coalition Bargaining: The Democratic Life Cycle in Western Europe. Oxford: Oxford University Press.

Royed, Terry (1996) 'Testing the Mandate Model in Britain and the United States: Evidence From the Reagan and Thatcher Eras', British Journal of Political Science 26: 45-80.

Stiglitz, Joseph E (2000) 'The Contribution of the Economics of Information to Twentieth Century Economics', Quarterly Journal of Economics 115: 1441-78.

- (2000) 'Delegation and Accountability in Parliamentary Democracies', European Journal of Political Research 37: 261-89. 
Strom, Kaare and Wolfgang C. Müller (1999) 'The Keys to Togetherness: Coalition Agreements in Parliamentary Democracies', Journal of Legislative Studies 5: 255-82.

Strom, Kaare, Wolfgang C. Müller, and Torbjörn Bergman (2003) Delegation and Accountability in Parliamentary Democracies. Oxford: Oxford University Press.

- (2008) Cabinets and Coalition Bargaining: The Democratic Life Cycle in Western Europe. Oxford: Oxford University Press.

Thies, Michael F (2001) 'Keeping Tabs On Partners: The Logic of Delegation in Coalition Governments', American Journal of Political Science 45: 580-98.

Timmermans, Arco (2003) High Politics in the Low Countries: An Empirical Study of Coalition Agreements in Belgium and The Netherlands. Aldershot: Ashgate.

— (2006) 'Standing Apart and Sitting Together: Enforcing Coalition Agreements in Multiparty Systems', European Journal of Political Research 45: 263-83.

Timmermans, Arco and Rudy B. Andeweg (2000) 'The Netherlands: Still the Politics of Accommodation?" in Wolfgang C. Müller and Kaare Strom (eds) Coalition Governments in Western Europe. Oxford: Oxford University Press.

Timmermans, Arco and Catherine Moury (2006) 'Coalition Governance in Belgium and The Netherlands: Rising Government Stability Against all Electoral Odds', Acta Politica 41: 389-407.

Tsebelis, George (2007) 'Coalition Theory: A Veto Players Approach', Mimeo.

Verzichelli, Luca (2008) 'Portfolio Allocation', in Kaare Strom, Wolfgang C. Müller, and Torbjörn Bergman (eds) Cabinets and Coalition Bargaining: The Democratic Life Cycle in Western Europe. Oxford: Oxford University Press.

Warwick, Paul V (1999) 'Getting the Assumptions Right: A Reply to Laver and Shepsle', British Journal of Political Science 29: 402-12.

- (1999) 'Ministerial Autonomy Or Ministerial Accomodation? Contested Bases of Government Survival in Parliamentary Democracies', British Journal of Political Science 29: 369-94. 


\section{Tables and Figures}

TABLE 1: DESCRIPTIVE STATISTICS (MAIN INDEPENDENT VARIABLES)

\begin{tabular}{|c|c|c|c|}
\hline $\begin{array}{c}\text { Country / } \\
\text { (Observations) }\end{array}$ & $\begin{array}{c}\text { Descriptive } \\
\text { Statistic }\end{array}$ & $\begin{array}{c}\text { Preference } \\
\text { Tangentiality }\end{array}$ & $\begin{array}{l}\text { Lik. Part. } \\
\text { Int. (MV) }\end{array}$ \\
\hline Austria & Mean & 4.06 & 0.61 \\
\hline (13) & St. Dev. & 1.14 & 0.23 \\
\hline Belgium & Mean & 3.79 & 0.22 \\
\hline$(27)$ & St. Dev. & 1.16 & 0.12 \\
\hline Denmark & Mean & 4.15 & 0.18 \\
\hline$(16)$ & St. Dev. & 1.34 & 0.1 \\
\hline Finland & Mean & 6.53 & 0.08 \\
\hline$(28)$ & St. Dev. & 1.62 & 0.04 \\
\hline France & Mean & 3.34 & 0.14 \\
\hline$(17)$ & St. Dev. & 1.67 & 0.15 \\
\hline Germany & Mean & 4.01 & 0.31 \\
\hline$(21)$ & St. Dev. & 1.23 & 0.17 \\
\hline Greece & Mean & 3.37 & 0.20 \\
\hline$(2)$ & St. Dev. & 1.38 & 0.08 \\
\hline Iceland & Mean & 3.92 & 0.26 \\
\hline (18) & St. Dev. & 1.02 & 0.11 \\
\hline Ireland & Mean & 4.29 & 0.24 \\
\hline (10) & St. Dev. & 3.07 & 0.14 \\
\hline Italy & Mean & 4.44 & 0.09 \\
\hline (33) & St. Dev. & 1.22 & 0.17 \\
\hline Luxembourg & Mean & 3.63 & 0.45 \\
\hline (16) & St. Dev. & 1.54 & 0.18 \\
\hline Netherlands & Mean & 2.62 & 0.16 \\
\hline (22) & St. Dev. & 0.94 & 0.08 \\
\hline Norway & Mean & 2.99 & 0.34 \\
\hline$(8)$ & St. Dev. & 0.43 & 0.06 \\
\hline Portugal & Mean & 1.20 & 0.33 \\
\hline (5) & St. Dev. & 1.68 & 0.14 \\
\hline Sweden & Mean & 4.06 & 0.18 \\
\hline (7) & St. Dev. & 1.00 & 0.07 \\
\hline Total & Mean & 4.06 & 0.23 \\
\hline$(243)$ & St. Dev. & 1.74 & 0.19 \\
\hline
\end{tabular}


TABLE 2: LOGISTIC REGRESSION ESTIMATES (ESTABLISHMENT OF CROSS-PARTISAN JUNIOR MINISTERS)

$\begin{array}{cccccc}\text { Robust } & \text { Clust. } & \text { Robust } & \text { Clust. } & \text { Robust } & \text { Clust. } \\ \text { S.E. } & \text { S.E. } & \text { S.E. } & \text { S.E. } & \text { S.E. } & \text { S.E. }\end{array}$

(1)

(2)

(3)

\begin{tabular}{|c|c|c|c|c|c|c|}
\hline \multirow{2}{*}{ Max. Poss. Cabinet Duration } & \multicolumn{2}{|c|}{0.020} & \multicolumn{2}{|c|}{0.028} & \multicolumn{2}{|c|}{0.029} \\
\hline & $(0.010)^{* *}$ & $(0.012)^{*}$ & $(0.011)^{* * *}$ & $(0.012)^{* *}$ & $(0.011)^{* * *}$ & $(0.012)^{* *}$ \\
\hline \multirow{2}{*}{ Cabinet Pref. Range (Polariz.) } & \multicolumn{2}{|c|}{-0.003} & \multicolumn{2}{|c|}{0.009} & \multicolumn{2}{|c|}{0.010} \\
\hline & $(0.006)$ & $(0.008)$ & $(0.007)$ & $(0.008)$ & $(0.007)$ & $(0.008)$ \\
\hline \multirow{2}{*}{ Preelectoral Agreement } & \multicolumn{2}{|c|}{1.255} & \multicolumn{2}{|c|}{0.931} & \multicolumn{2}{|c|}{1.103} \\
\hline & $(0.655)^{*}$ & $(0.891)$ & $(0.691)$ & $(0.848)$ & $(0.710)$ & $(0.894)$ \\
\hline \multirow{2}{*}{ Permanent Committees } & \multicolumn{2}{|c|}{-2.025} & \multicolumn{2}{|c|}{-2.150} & \multicolumn{2}{|c|}{-2.109} \\
\hline & $(0.422)^{* * *}$ & $(1.179)^{*}$ & $(0.542)^{* * *}$ & $(1.285)^{*}$ & $(0.528) * * *$ & $(1.232)^{*}$ \\
\hline \multirow{2}{*}{ Committees' Power } & \multicolumn{2}{|c|}{0.472} & \multicolumn{2}{|c|}{0.526} & \multicolumn{2}{|c|}{0.552} \\
\hline & $(0.156)^{* * *}$ & $(0.449)$ & $(0.150)^{* * *}$ & $(0.387)$ & $(0.151)^{* * *}$ & $(0.374)$ \\
\hline \multirow{2}{*}{ Preference Tangentiality } & & & \multicolumn{2}{|c|}{-0.490} & \multicolumn{2}{|c|}{-0.706} \\
\hline & & & $(0.107)^{* * *}$ & $(0.164)^{* * *}$ & $(0.163)^{* * *}$ & $(0.230)^{* * *}$ \\
\hline \multirow{2}{*}{ Lik. of Partners' Interact. (MV) } & & & \multicolumn{2}{|c|}{-2.714} & \multicolumn{2}{|c|}{-6.700} \\
\hline & & & $(1.024)^{* * *}$ & $(1.673)$ & $(2.186)^{* * *}$ & $(3.195)^{* *}$ \\
\hline \multirow{2}{*}{ Tangentiality * Lik. Part. Int. (MV) } & & & & & \multicolumn{2}{|c|}{0.981} \\
\hline & & & & & $(0.528)^{*}$ & $(0.579)^{*}$ \\
\hline \multirow{2}{*}{ Constant } & \multicolumn{2}{|c|}{-2.950} & \multicolumn{2}{|c|}{-1.364} & \multicolumn{2}{|c|}{-0.741} \\
\hline & $(1.351)^{* *}$ & $(3.589)$ & $(1.364)$ & $(3.423)$ & $(1.363)$ & $(3.331)$ \\
\hline Observations & \multicolumn{2}{|c|}{244} & \multicolumn{2}{|c|}{243} & \multicolumn{2}{|c|}{243} \\
\hline Pseudo-R $^{2}$ & \multicolumn{2}{|c|}{0.112} & & & & \\
\hline
\end{tabular}

$* * * \mathrm{p}<0.01, * * \mathrm{p}<0.05, * \mathrm{p}<0.1$

Standard errors in parentheses 


\section{TABLE 3: LINEAR REGRESSION ESTIMATES (SHARE OF CROSS-PARTISAN JUNIOR MINISTERS)}

$\begin{array}{cccccc}\text { Robust } & \text { Clust. } & \text { Robust } & \text { Clust. } & \text { Robust } & \text { Clust. } \\ \text { S.E. } & \text { S.E. } & \text { S.E. } & \text { S.E. } & \text { S.E. } & \text { S.E. }\end{array}$

Max. Poss. Cabinet Duration

Cabinet Pref. Range (Polariz.)

Preelectoral Agreement

Permanent Committees

Committees' Power

Preference Tangentiality

Lik. of Partners' Interact. (MV)

Pref. Tangentiality * Lik. Part. Int. (MV)

$$
\text { Constant }
$$

(1)

$\begin{array}{cc}0.003 & 0.004 \\ (0.001)^{* *}(0.001)^{*} & (0.001)^{* * *} \quad(0.001)^{* * *} \\ 0.000 & 0.000\end{array}$

$\begin{array}{llll}(0.001) & (0.001) & (0.001) & (0.001)\end{array}$

(0.073)

$(0.144)$

$-0.090$

$(0.042)^{* *} \quad(0.140)$

0.020

(0.014)

(0.042)

(2)
(3) 
TABLE 4: LOGISTIC REGRESSION ESTIMATES (EXISTENCE OF A COMPREHENSIVE POLICY AGREEMENT)

$\begin{array}{cccccc}\text { Robust } & \text { Clust. } & \text { Robust } & \text { Clust. } & \text { Robust } & \text { Clust. } \\ \text { S.E. } & \text { S.E. } & \text { S.E. } & \text { S.E. } & \text { S.E. } & \text { S.E. }\end{array}$

(1)

(2)

(3)

Max. Poss. Cabinet Duration

\begin{tabular}{cccccc}
0.015 & \multicolumn{2}{c}{0.011} & \multicolumn{2}{c}{0.011} \\
$(0.008)^{*}(0.010)$ & $(0.008)$ & $(0.010)$ & $(0.009)$ & $(0.010)$ \\
-0.016 & & -0.006 & -0.006
\end{tabular}

Cabinet Pref. Range (Polariz.) $(0.006) * * * \quad(0.006) * * \quad(0.007) \quad(0.011)$

$(0.007) \quad(0.010)$

Preelectoral Agreement $-0.151$

$\begin{array}{llll}(0.506) & (0.969) & (0.493) & (0.846)\end{array}$

$(0.503)^{-0.610}(0.844)$

Permanent Committees

0.183

0.616

0.608

$\begin{array}{llll}(0.354) & (0.641) & (0.400) & (0.731)\end{array}$

Committees' Power

0.030

(0.117) (0.320)

(0.126) (0.351)

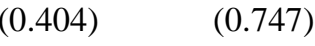

$(0.117)$

(0.320)

$-0.243$ 0.034

Preference Tangentiality

Lik. of Partners' Interact. (MV)
$(0.101)^{* *} \quad(0.127)^{*}$
1.816

$(0.791)^{* *} \quad(1.392)$

(0.126) (0.348)

Pref. Tangentiality * Lik. Part. Int. (MV)

$$
\text { Constant }
$$$$
-1.003
$$

$$
\text { (1.041) }
$$

(2.732)

(1.147)

$-0.356$

(3.004)

244

243

0.069 
FIGURE 1: PORTFOLIO LATTICES AND TYPES OF PREFERENCES

( LEFT: Overlapping Preferences ; RIGHT: Tangential Preferences )
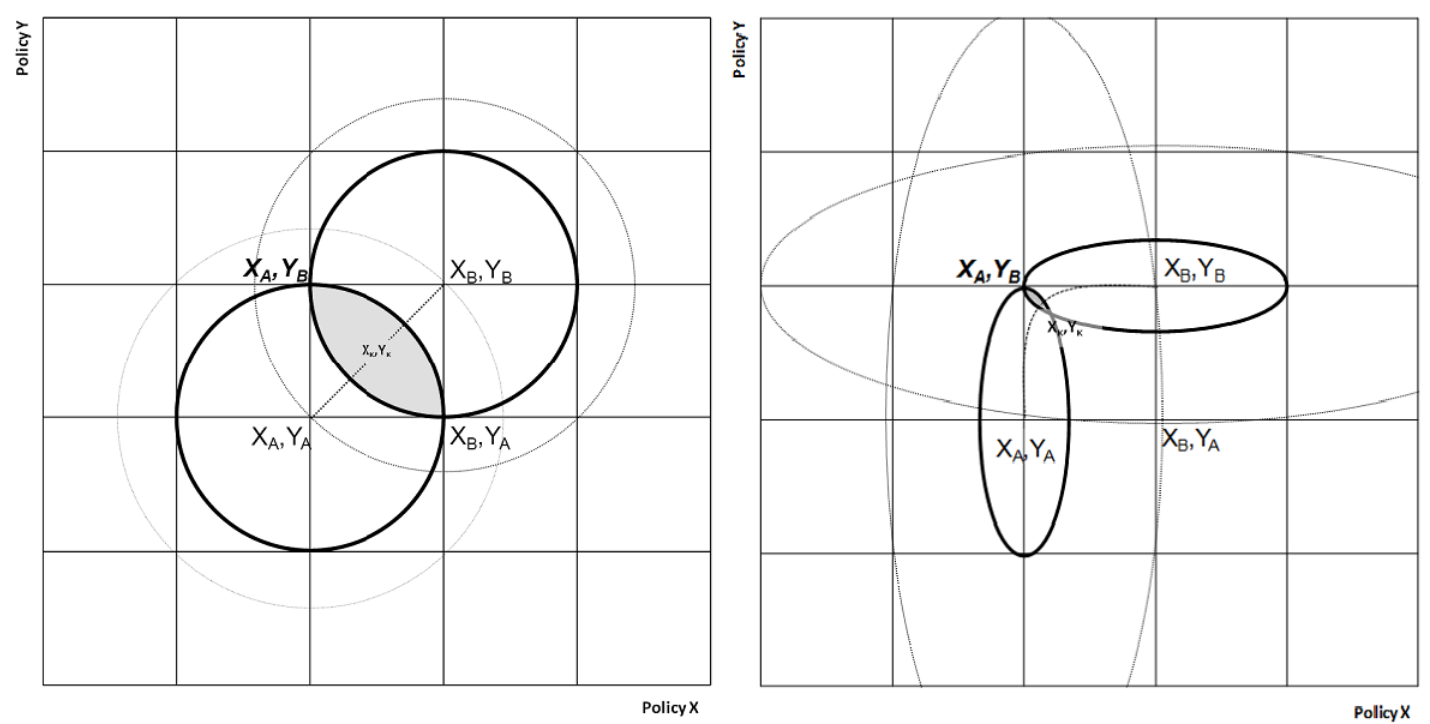
FIGURE 2: NECESSITY OF COALITION CONTROL MECHANISMS (DIAGRAM)

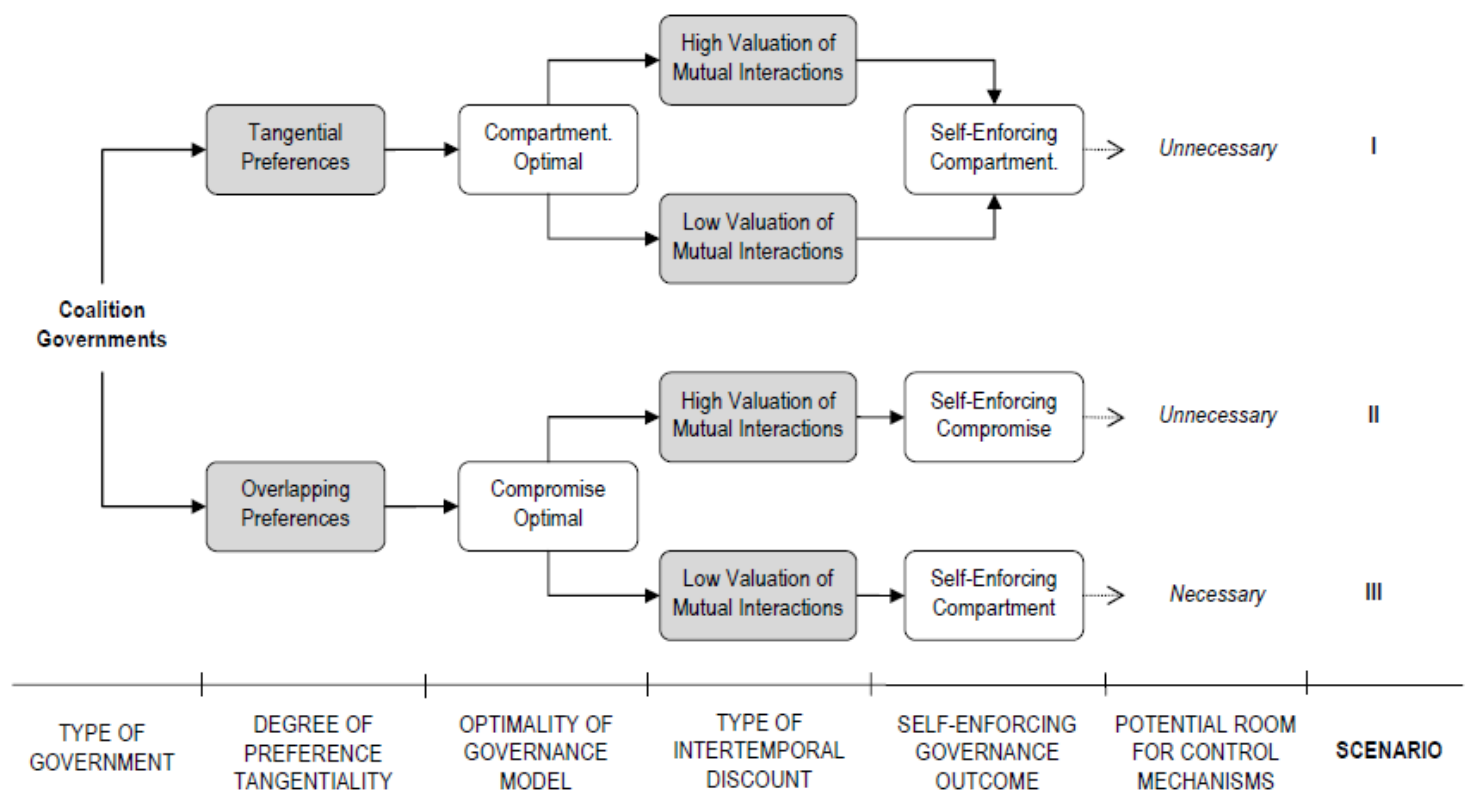


FIGURE 3: NECESSITY OF COALITION CONTROL MECHANISMS (MATRIX)

PARTNERS' VALUATION OF FUTURE INTERACTIONS

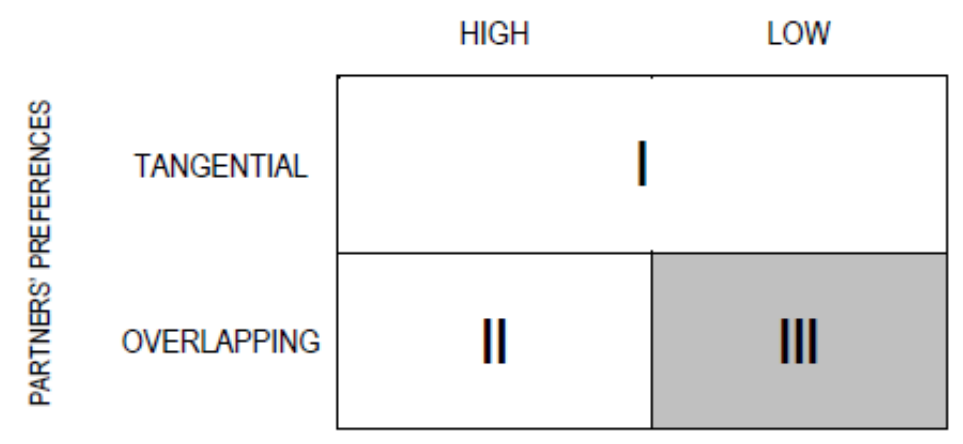


FIGURE 4: INTERACTIVE EFFECT ON THE LIKELIHOOD OF

ESTABLISHING CROSS-PARTISAN JUNIOR MINISTERS

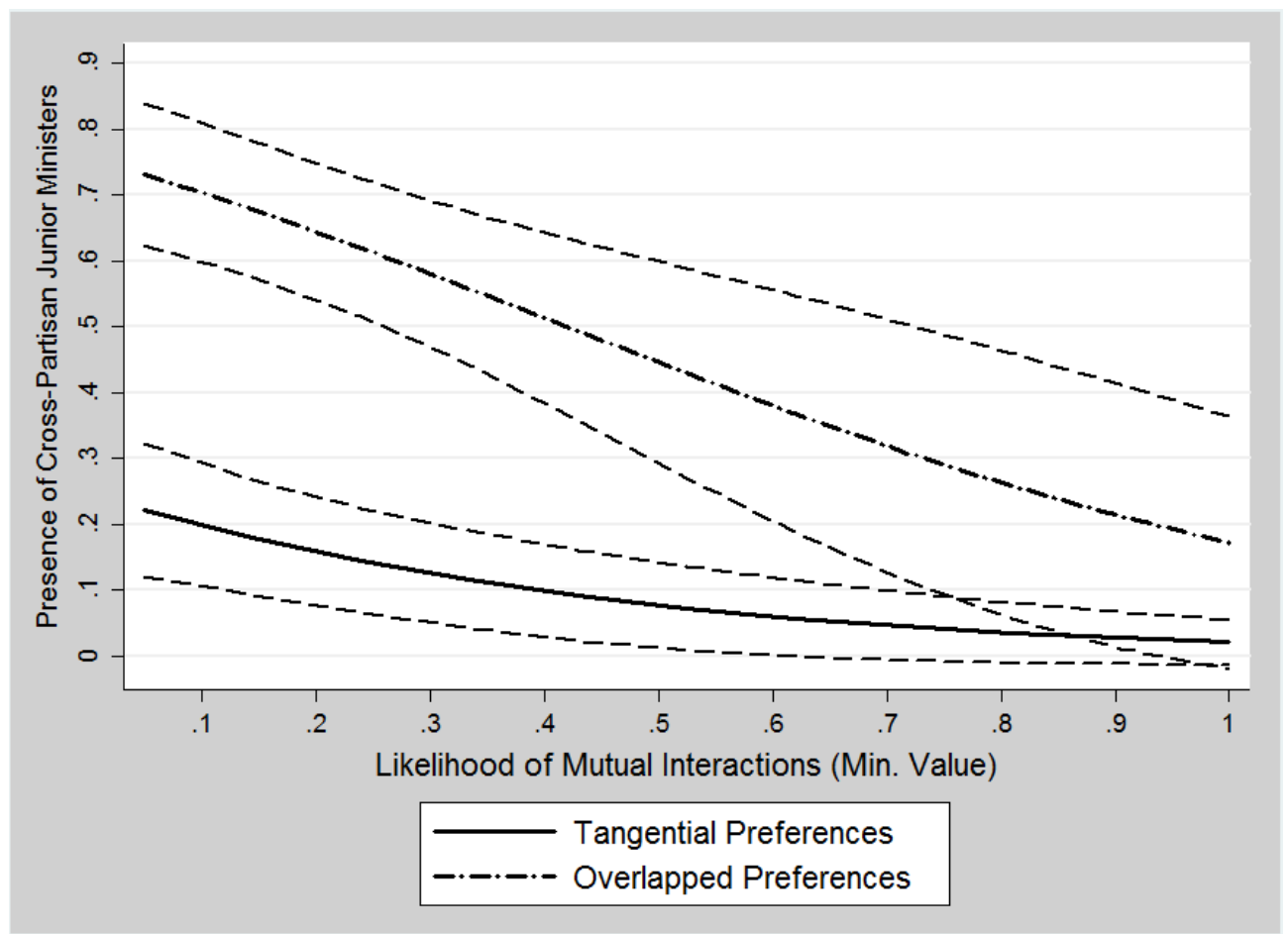

